\title{
In-situ Digital Image Correlation for Fracture Analysis of Oxides Formed on Zirconium Alloys
}

\author{
P. Platt ${ }^{a}$, D. Lunt ${ }^{a}$, E. Polatidis ${ }^{a}$, M. R. Wenman ${ }^{b}$, M. Preuss ${ }^{a}$ \\ aUniversity of Manchester, School of Materials, Materials Performance Centre, Manchester, M13 9PL, \\ UK
}

${ }^{b}$ Centre for Nuclear Engineering and Department of Materials, Imperial College London, London SW7

$2 A Z$

*Tel: 07753431684. email: Philip.Platt@manchester.ac.uk

\begin{abstract}
Repeated breakdown of the protective oxide layer can be a key factor in the oxidation of zirconium alloys. Hence, accurate measurement of the oxide fracture strength is crucial for simulating the oxidation of these alloys. High resolution digital image correlation was applied to SEM images taken during in-situ tensile loading of oxidised ZIRLOTM. Bi-axial strain measurements obtained during crack formation in the oxide films were converted into stress, and fitted to Weibull distributions to predict the oxide failure strength. Analysis highlights the impact of surface roughness. Samples polished prior to oxidation gave a fracture strength of $\sim 1.6 \mathrm{GPa}$.

Keywords: Zirconium, Oxide, Digital Image Correlation, Synchrotron X-Ray Diffraction, Fracture, Weibull
\end{abstract}

\section{Introduction}

Since their introduction as nuclear fuel cladding for pressurised water reactors in the 1960's, zirconium alloys have been researched significantly. As a degradation mode, understanding oxidation and corrosion has been of high priority due to its capacity to introduce hydrogen $[1,2]$, induce deformation in the metal substrate [3,4], and thin the cladding by material consumption [5]. More recently, research in this area has been driven by the need for a mechanistic understanding of the corrosion process [6]. Central to this is the development of simulations that can capture mechanical aspects of corrosion as a process [7]. However, for these simulations to be valid an accurate definition of the oxides fracture strength is required.

During oxidation in aqueous autoclave environments, zirconium alloys have been shown to demonstrate cyclical corrosion kinetics every 1.5-4.3 $\mu \mathrm{m}$ of oxide growth [8-14]. The end of each cycle is associated with a breakdown of the protective barrier layer, leading to acceleration in the corrosion kinetics. These accelerations in the corrosion kinetics have repeatedly been linked with the formation of a network of cracks running parallel to the metal-oxide interface [15-19]. The lateral cracks form very close to the 
metal-oxide interface, and travel through the protective barrier layer [16-19]. It has also been proposed that the region of tri-axial tensile stress, ahead of these advancing cracks, could destabilise the tetragonal phase present at the metal-oxide interface, leading to further nano-scale cracking [20].

Fracture of the oxide layer has also been shown to be of importance during high temperature oxidation of zirconium alloys. In order to understand oxidation during loss of coolant accidents (LOCA) many authors have researched oxidation of zirconium alloys in the $600-1200^{\circ} \mathrm{C}$ temperature range [21-25]. Whether oxidation occurs in air or steam zirconium alloys typically demonstrate a transition to accelerated breakaway corrosion kinetics [21-23]. Research has indicated this acceleration is associated with the formation of large cracks perpendicular to the metal-oxide interface, and the formation of a defective, heavily-fractured oxide layer $[21,24,25]$. Although in this study oxides are formed at a much lower temperature, the results could still be of value to research carried out at high temperatures.

Digital image correlation (DIC) is a technique that provides full field displacement information on the surface of a sample [26]. In doing so it is possible to calculate the localised strain field of a deforming material under mechanical loading [27]. The sensitivity to localised displacements, and therefore strain fields, makes it an ideal tool for detection of crack nucleation and propagation [28]. As such, it allows for early identification of cracks, and definition of the localised strains at which the cracks form.

The primary aim of this work is to define a fracture stress and strain for oxides formed on zirconium alloys. It is shown that gold remodelling and in-situ digital image correlation offer a route to analysing the fracture strength of thin oxides and coatings.

\section{Experimental Method\& Material Characterisation}

\subsection{Sample Preparation and Oxidation}

For tensile testing, samples of ZIRLOTM material, with composition shown in Table 1 [29], were machined into 7 dog-bone tensile samples, with a gauge volume of $26 \times 3 \times 0.45 \mathrm{~mm}^{3}$. Two methods of sample preparation were used prior to oxidation. The first three samples were pickled in a dilute hydrofluoric acid solution ( $\mathrm{HF} 10$ vol.\%, $\mathrm{NHO}_{3} 45$ vol.\% and $\mathrm{H}_{2} \mathrm{O} 45$ vol.\%)[8,30]. The other four samples were lightly ground to 800 grit, polished with $6 \& 1 \mu \mathrm{m}$ diamond paste, and finished with a colloidal silica polishing solution. These preparations were carried out to remove any damage in the near surface region of the as-received material, and to generate planar surfaces. All samples were subsequently oxidised in a chamber furnace (in air) at $360^{\circ} \mathrm{C}$ for 20 days giving an average weight gain of $18.2 \pm 1.7 \mathrm{mg}$. For oxide stress characterisation, five coupons $\left(30 \times 20 \times 0.45 \mathrm{~mm}^{3}\right)$ of the same ZIRLO ${ }^{\mathrm{TM}}$ material were pickled in a dilute hydrofluoric solution and then oxidised in autoclave at $360^{\circ} \mathrm{C}$ for 20 days, in simulated primary water (pure $\mathrm{H}_{2} \mathrm{O}$ with 2ppm lithium hydroxide and 1000ppm of boric acid), at a pressure of $18 \mathrm{MPa}$. This gave an average weight gain of $17.3 \pm 1.7 \mathrm{mg}$. These weight gains can be related to oxide thickness using the relationship that $15 \mathrm{mg} / \mathrm{dm}^{2}$ weight gain equals $1 \mu \mathrm{m}$ of oxide thickness [16]. Based on the weight 
gain, the tensile dog-bone samples demonstrated an average oxide thickness of $1.21 \pm 0.11 \mu \mathrm{m}$, and the coupons an average oxide thickness of $1.18 \pm 0.11 \mu \mathrm{m}$.

Preparation by polishing or pickling resulted in different surface profiles. This largely resulted from the strong preferential etching effect of the pickling process. After oxidation raised areas could be observed that correlate with the size and shape of the underlying metal grain structure. The surface roughness was defined using a Keyence VK-X200K 3D laser scanning microscope. This was done by taking 10 line profiles, $96 \mu \mathrm{m}$ in length, for a pickled sample and a polished sample after oxidation. The parameter used to define the roughness was the root mean square of the profile slope (Rdq) as discussed in [16], defined using Eq.1.

$$
R_{d q}=\sqrt{\frac{1}{N} \sum_{i=1}^{N} \Delta_{i}^{2}}
$$

where $\Delta$ is the slope between two given points, taken at $\mathrm{N}$ number of intervals across the interface. The polished samples gave a median $R_{d q}$ of $0.101 \pm 0.007$, whilst the pickled sample gave a median $R_{d q}$ of $0.569 \pm 0.051$. This indicates that the oxide surface is much rougher for samples prepared via the pickling processes than the polished samples.

\subsection{Residual Stress/Strain Characterisation}

Characterisation of the residual stress in oxides formed on the 5 ZIRLO ${ }^{\mathrm{TM}}$ coupons was performed using synchrotron X-ray diffraction (SXRD) at the EDDI beam-line at BESSY II (Berlin, Germany) [31]. The experimental setup allowed for rapid acquisition of the diffraction peaks in the energy range of 20-150 $\mathrm{keV}$ utilizing a polychromatic beam in energy dispersive mode, more details can be found in [30]. Inplane residual stresses in the oxide layer $\left(\sigma_{11}=\sigma_{22}\right)$ were determined by tilting the samples through a range of $\psi$ angles, measuring the diffraction pattern at each angle and applying the $\sin ^{2} \psi$ technique. The oxide reflections of interest for residual strain characterisation are $(\overline{1} 11)_{m}$ and $(101)_{t}$. Additionally, the $(111)_{m}$ reflection is necessary for calculation of tetragonal phase fraction using the Garvie-Nicholson formula (Eq.2) [32].

$$
f_{\text {tet }}=\frac{I_{t(101)}}{I_{t(101)}+I_{m(111)}+I_{m(\overline{1} 11)}}
$$

where $l$ is the integrated intensity for each reflection, $t$ denotes the tetragonal phase and $m$ denotes the monoclinic phase. Such residual stress and phase fraction analysis methodology has been extensively applied previously to these materials in $[3,30]$. Table 2 shows the residual stresses calculated for the monoclinic and tetragonal phases, the tetragonal phase fractions and the average in-plane stress in the oxide layer. This average in-plane stress is calculated by weighting the in-plane stresses in each phase against the phase fraction (Eq.3), as described in [3]. 


$$
\sigma_{\text {avg }}=\left(f_{t} \sigma_{t}\right)+\left(f_{m} \sigma_{m}\right)
$$

The average in-plane stress was converted to strain by assuming that a biaxial stress condition exists (i.e. stress perpendicular to the specimen surface, $\sigma_{33}$, is assumed to be zero and $\sigma_{11}=\sigma_{22}$ ). Thus the inplane strains, $\varepsilon_{11}$ and $\varepsilon_{22}$, can be obtained by:

$$
\varepsilon_{11}=\varepsilon_{22}=\frac{\sigma_{11}}{E}(1-v)
$$

Using the elastic properties of the bulk material adopted from previous work [3,30], $E$ is the elastic modulus for the oxide (253 GPa), $v$ is the Poisson's ratio for the oxide $(0.282)$, and $\sigma_{11}$ is the in-plane residual stress in the oxide layer. Taking the mean of the 5 samples in Table 2 gives a characteristic compressive residual stress of $-1455 \pm 83 \mathrm{MPa}$.

Using Eq.4 gives an in-plane strain of $-0.00413 \pm 0.00024$, which should be the tensile strain required to reduce either of the $\sigma_{11}$ or $\sigma_{22}$ residual stress components to zero. Although Eq.4 has been used previously to relate residual stress to strain in biaxial compressed thin film oxides [33], definition of this problem can be calculated by a number of routes [3], which could impact the final value for residual strain.

\subsection{Digital Image Correlation (DIC) and Mechanical Testing}

After oxidation, the gold remodelling technique was used to produce a fine speckle pattern on the surface of the samples. First an Edwards S150B sputter coater was used to apply a thin layer of gold of $25-40 \mathrm{~nm}$ in thickness. Samples were then heated in a water vaporisation environment at a temperature of $270-300^{\circ} \mathrm{C}$, for up to $3.5 \mathrm{hrs}$, in order to remodel the gold particles. This process is described in detail in [27]. Gold remodelling converts a thin, fairly homogenous, layer of gold into a pattern of gold speckles on the surface of the sample. The speckle pattern morphology is controlled by the thickness of the gold film, and the temperature, time and humidity of the remodelling environment.

Following this procedure, samples were mounted in a Kammrath-Weiss $5 \mathrm{kN}$ micro-mechanical tester and installed on a FEI Quanta 650 field emission gun scanning electron microscope, operated at $20 \mathrm{keV}$. Samples were displaced at a rate of $5 \mu \mathrm{m} / \mathrm{s}$, and measurements were undertaken upon stopping the tensile machine at specific elongation increments. This cycle of displacing and imaging was carried out between 20-30 times, with the initial displacement increments being larger to overcome the residual strain in the oxide layer. Typically, the maximum total strain was $\sim 1.6 \%$.

The choice of magnification for SEM imaging during testing was determined by the speckle size once the sample was mounted and placed in the SEM chamber. Fig.1a shows an image of the gold pattern, formed on samples polished prior to oxidation, at high magnification. It can be seen that the gold speckles have a uniform shape and spacing. Fig.1b shows an image of the gold pattern formed on a sample that was pickled prior to oxidation. Here, the size and distribution are less homogenous, and the variation in surface topography interferes with the contrast. These images were acquired at a working 
distance (WD) of $6.8 \mathrm{~mm}$, which is significantly lower than the WD imposed by the micro tester of $>20 \mathrm{~mm}$ for in-situ tensile testing. Fig.1c shows a high magnification image of the rougher surface at a WD of $\sim 20 \mathrm{~mm}$, and the contrast has been reduced even further. When imaging for DIC analysis individual gold speckles should to be $\sim 3$ pixels in diameter. As such, images produced for DIC were taken at much lower magnification than the images shown. For the rougher samples only the largest speckles gave appropriate contrast, and therefore a lower magnification was used. For each of the three samples that where pickled prior to oxidation a surface area of $74 \times 74 \mu \mathrm{m}^{2}$ was analysed, whilst for each of the four samples that where polished an area of $59 \times 59 \mu \mathrm{m}^{2}$ was analysed.

DIC analysis of these sequences of images was carried out using DaVis software [34]. Although each image was centred after straining, the images were shift-corrected relative to the first image at the start of the DIC processing. Images were tested with $6 \times 6,8 \times 8,12 \times 12$ and $16 \times 16$ pixel interrogation windows. Increasing the size of interrogation windows, also known as sub-regions, reduces the noise but also the spatial resolution. A window size of $12 \times 12$ pixels was chosen as this gave the best balance between minimising scatter when plotting the strain components, and defining the detail of the individual crack formation. The correlated digital images were assessed along with the backscattered images to define individual crack initiations perpendicular to the loading direction. In order to minimise the impact of noise, the strain in the loading direction would then be defined over a rectangular area close to the initiating crack. Averaging over an area also helped mitigate many of the issues associated with the rougher surface finish of some of the samples. As crack formation would occur during a step displacement, the actual fracture strain is a value somewhere between the two strain values at the beginning and end of the step. To this end, results of the residual strains in the oxide defined using SXRD (see section 2.3) were used for determining the effective strains by DIC.

\subsection{Weibull Statistical Analysis}

For each of the different sample preparations the fracture strain was defined for over thirty cracks. Given the substantial variation that can occur for the fracture strength of ceramics and oxides, a Weibull statistical analysis has been applied to the resulting fracture data. Weibull defined a 2 parameter statistical analysis, which can be used to give the survival probability using Eq.5.

$$
P_{s}=\exp \left\{-\left(\frac{\sigma}{\sigma_{0}}\right)^{m}\right\}
$$

where $P_{s}$ is the survival probability of a sample from a batch of samples with identical volumes, $\sigma$ is applied stress, $m$ is the Weibull modulus, and $\sigma_{0}$ is a scaling parameter defined when $P_{s}=0.37$. The Weibull modulus $(\mathrm{m})$ can give an indication of the material defect density, but is also affected by the sample geometry [35]. In order to plot $\mathrm{P}_{\mathrm{s}}$ against fracture strength, the fracture values for a given set are arranged in ascending order, and then assigned a number from 1 to $\mathrm{N}$, where $\mathrm{N}$ is the total number of samples in the set. $P_{s}$ can then be estimated using the equation $[n /(N+1)]$. In this work a non-linear 
least squares regression, based on the Levenberg-Marquardt algorithm, is used to define $\sigma_{0}$. A graphical method can also be used to define the constant m. Eq.5 is first transformed into Eq.6.

$$
\ln \left\{\ln \left(\frac{1}{P_{s}}\right)\right\}=m \ln \left(\frac{\sigma}{\sigma_{0}}\right)
$$

Here, the constant $m$ can be defined as the slope of a linear fit when plotting $\ln \left\{\ln \left(\frac{1}{\left(1-P_{s}\right)}\right)\right\}$ against $\ln \left(\frac{\sigma}{\sigma_{0}}\right)$. This is a form of 2-parameter Weibull statistical analysis. A key limitation with this approach is that extrapolating to low probabilities can result in unrealistically low, or even negative, fracture stresses. Eq.7 shows a 3-parameter approach that uses a $\sigma_{\min }$ minimum stress component to avoid this problem [36,37].

$$
P_{s}=\exp \left\{-\left(\frac{\sigma-\sigma_{\min }}{\sigma_{0}-\sigma_{\min }}\right)^{m}\right\}
$$

Here, the theoretical minimum fracture stress $\left(\sigma_{\mathrm{min}}\right)$ is distinct from the lowest recorded fracture stress $\left(\sigma_{11 \mathrm{~min}}\right)$ discussed later. Plots of Equations 5 and 7 give the cumulative density functions, for the $2 \& 3$ parameter approaches. More information related to the shape of the Weibull distributions can be obtained when analysing the probability density function plots. The definitions for the $2 \& 3$ parameter approaches here can be obtained using Equations 8 \& 9 .

$$
\begin{gathered}
P D F=\frac{m}{\sigma_{0}}\left(\frac{\sigma}{\sigma_{0}}\right)^{m-1} \cdot \exp \left\{-\left(\frac{\sigma}{\sigma_{0}}\right)^{m}\right\} \\
P D F=\frac{m}{\sigma_{0}-\sigma_{\min }}\left(\frac{\sigma-\sigma_{\min }}{\sigma_{0}-\sigma_{\min }}\right)^{m-1} \cdot \exp \left\{-\left(\frac{\sigma-\sigma_{\min }}{\sigma_{0}-\sigma_{\min }}\right)^{m}\right\}
\end{gathered}
$$

\section{Results}

\subsection{Stress-Strain Analysis}

Fig. 2a, $\mathrm{b}$ and $\mathrm{c}$ show the $\varepsilon_{11}$ strain maps extracted from DaVis for a polished sample after strains of 1.3 $\%, 1.4 \%$ and $1.55 \%$. The loading $\left(\varepsilon_{11}\right)$ direction is parallel to the width of the images, and perpendicular to the direction of the cracks. They show two cracks initially forming, growing in length, and becoming what can be referred to as channel cracks.

Fig.3a shows the $\varepsilon_{11}$ and $\varepsilon_{22}$ strains extracted using DIC for each of the 60 fracture events observed in oxides across a total of 7 samples. Fig. $3 b$ shows the modified $\varepsilon_{11}$ and $\varepsilon_{22}$ components after the addition of the -0.00413 residual strain in the oxide layer defined using SXRD. The error bars are defined by the size of the strain step over which the fracture event occurs. After addition of the residual strain, the minimum-maximum fracture strains are 0.0032-0.0105 for the samples pickled prior to oxidation, and 0.0074-0.0118 for samples polished prior to oxidation. 
The relationship between $\varepsilon_{11}$ and $\varepsilon_{22}$ is complicated. This is in part because the areas analysed are highly localised, but also because of the difference in Poisson's ratio between the metal and the substrate. Assuming that the out-of-plane stress $\left(\sigma_{33}\right)$ in the oxide is zero, the $\sigma_{11}$ fracture stresses can be calculated using a plane stress formulation (Eq.10).

$$
\sigma_{11}=\frac{E}{\left(1-v^{2}\right)}\left(\varepsilon_{11}+v \varepsilon_{22}\right)
$$

where $\varepsilon_{11}$ is the strain in the loading direction, $\varepsilon_{22}$ is the strain in the transverse direction. The mean strain and minimum stress values are shown in Table 3 . The minimum stress required to fracture $\left(\sigma_{11 \mathrm{~min}}\right)$ an oxide formed on a pickled sample is $0.41 \mathrm{GPa}$, and $1.05 \mathrm{GPa}$ for an oxide formed on a polished sample.

\subsection{Fracture Analysis}

For the 2-parameter analysis, the plot of fracture stress against survival probability is shown in Fig.4, and the graphical method used to define the constant $m$ is shown in Fig.5. In Fig.4 it can be seen that the tails of the curves are not particularly sharp, and are not a good fit. Therefore, the curves will predict that fracture is possible at unrealistically low stress levels. Considering Fig.5, some of the points appear to align vertically, allowing estimation of theoretical minimum stresses $\left(\sigma_{\mathrm{min}}\right)$ of $0.3 \mathrm{GPa}$ for the pickled samples and 0.8 GPa for the polished samples. Using Eq.7 and a non-linear regression analysis, two different assessments of the 3-parameter have been made and shown in Fig.6. For Set 1, $\sigma_{0}$ has been set as the same value defined for the 2-parameter approach, with only $m$ allowed to vary. For Set 2 , both $\sigma_{0}$ and $m$ are allowed to vary. The outputs have been compiled into Table 3 , and it can be seen that for both the Set 1 and Set 2 non-linear regressions the resulting constants are identical.

Using both the 2 \& 3 parameter Weibull statistical analysis the calculated fracture strengths $\left(\sigma_{0}\right)$ are $\sim 1.12 \mathrm{GPa}$ for oxides formed on the pickled samples and $1.57 \mathrm{GPa}$ for oxides formed on the polished samples. The oxides grown on either sample surface have $100 \%$ probability of fracture when subjected to a stress of $\sim 2 \mathrm{GPa}$. The 3-parameter analysis (Fig.6) can be seen to give a better fit at the beginning and ends of the data sets, when compared with the 2-parameter analysis (Fig.4). Figure 7 shows plots of the probability density function (PDF). Changing to the 3-parameter analysis only has a distinct effect on the tails of the PDFs, and does not produce a substantial impact on the overall shapes of the curves. The peak position is, however, marginally shifted to lower values for the 3-paramter fits. Although the $\mathrm{m}$ values for the Pickled and Polished samples appear to have converged in the 3-parameter analysis (Table 3), the PDFs are still very distinct from each other.

\section{Discussion}


Although there does not appear to be values in literature for the fracture strengths of oxides formed thermally on zirconium alloys, the fracture strength of doped and undoped tetragonal and monoclinic manufactured zirconia ceramics have been determined to be in the range of $220-745 \mathrm{MPa}$ [38-40]. These values are comparable only with the lower range of the oxide grown on the pickled samples. However, the thickness of the test samples in literature was on the order of $\sim 1 \mathrm{~mm}$, the measured grain sizes ranged from $110 \mathrm{~nm}$ to $480 \mathrm{~nm}$, and the sintering process is known to form pores on the scale of $20-80 \mu \mathrm{m}$ [38-40]. This can be compared with the thermally grown oxide layer in the present case, which is $1.21 \pm 0.11 \mu \mathrm{m}$ thick and has typically a grain size on the order of $\sim 30 \mathrm{~nm}[41,42]$. Based on previously reported transmission electron microscopy (TEM) these oxide layers contain nano-cracks in range of $30-100 \mathrm{~nm}$ and nano-pores in the range of $10-30 \mathrm{~nm}$ [43]. The fracture strength of ceramics is controlled by the size of the largest defect. Therefore, the observed differences between the fracture strength measured on the thermally grown oxide film and manufactured zirconia ceramics is to be expected.

It can be seen from Fig. 4 that there is a larger range in fracture stresses for the regions of oxide formed on the pickled sample compared to the polished sample. While the maximum-recorded fracture stresses are very similar for the two conditions, the minimum recorded fracture stress is much lower ( 400 MPa) for samples that were pickled prior to oxidation. The minimum recorded fracture stress $\left(\sigma_{11 \mathrm{~min}}\right)$ is distinct from the theoretical minimum $\left(\sigma_{\mathrm{min}}\right)$ used as a constant to define the 3-parameter Weibull analysis. This variation between the sample preparations is also demonstrated by the difference in the value for the constant $\mathrm{m}$ (Table 3), particularly for the 2-parameter analysis.

As discussed in [35], the constant $m$ can be influenced by sample geometry. Although the roughness measurements were taken from the oxide surface, the origin of the roughness is the etching effect on the surface of the metal created by the pickling sample preparation. As such, rather than a variation in oxide roughness this is closer to a variation in the planarity and geometry of the oxide layer as a thin film. Given that the mean oxide layer thickness is only $1.21 \pm 0.11 \mu \mathrm{m}$, even a small variation in planarity could have a dramatic impact on the way in which localised stresses develop under load. It is not clear how or why oxides formed on these different substrates would demonstrate different defect densities.

Comparison of the constant $m$ produced by the $2 \& 3$ parameter approaches (Table 3 ) raises questions about the information that $m$ is providing. The fact that $m$ converges in the 3-parameter analysis without leading to a significant change in the PDFs (Fig.7) could indicate that $\mathrm{m}$ is closer to a curve fitting parameter rather than a fundamental material constant defined by defect density [35-37].

During oxidation of zirconium alloys there are a number of mechanical phenomena that can contribute to, or directly induce, fracture in the oxide layer. These include the impact of initial surface roughness [44], interfacial roughness which develops during oxidation $[7,15-17,45]$, and the tetragonal to monoclinic phase transformation $[20,46]$. These cracks have been directly linked with breakdown of the protective character of the oxide and acceleration in the corrosion kinetics, via the creation of fast ingress routes for oxygen containing species $[7,11,12,16,17]$. They may also be linked with porosity present in the oxide microstructure [43]. However, previously published fracture strength data relates to manufactured stabilised zirconia, which is several orders of magnitude greater in terms of both sample 
size, and defect size [38-40]. This work determines the fracture strength of oxides formed thermally on zirconium alloys, and offers a route to investigate other thin films and coatings. It also demonstrates the potential impact of the surface roughness in promoting fracture of the oxide layer, which could reduce the protective nature of the oxide layer [44].

\section{Conclusions}

The fracture strengths of oxides formed on ZIRLOTM have been defined using a combination of synchrotron X-Ray diffraction, high resolution digital image correlation and Weibull statistical analysis. It was found that surface preparation prior to oxidation plays a large role in the recorded fracture strength of the thermally grown oxide. Increased surface roughness gave a larger range in fracture strains, and lower minimum fracture strengths. For samples that were mechanically polished prior to oxidation failure strengths of $\sim 1.57 \mathrm{GPa}$ are demonstrated. Samples that where pickled prior to oxidation had a much rougher surface and the concurrent difference in geometry of the thin film led to failure strengths of $\sim 1.12 \mathrm{GPa}$.

\section{Acknowledgments}

Thanks go to Rolls-Royce plc for providing project funding and Westinghouse for providing material. Additional thanks go to Troy Liu and Philipp Frankel for development of testing parameters and technical insight. The infrastructural support of the Materials Performance Centre at the University of Manchester is also greatly appreciated. Michael Preuss also acknowledges EPSRC Leadership Fellowship funding (EP/I005420/1). 


\section{Tables \& Figures}

Table 1 Composition of recrystallised ZIRLO ${ }^{\text {TM }}$ Sheet

\begin{tabular}{lllll}
\hline Material & $\mathrm{Sn}$ & $\mathrm{Fe}$ & $\mathrm{Cr}$ & $\mathrm{Nb}$ \\
\hline ZIRLOTM $^{\text {TM }}$ & 0.92 & 0.09 & $<0.01$ & 0.91 \\
\hline
\end{tabular}

Table 2 Residual strains and tetragonal phase fraction for oxides formed on ZIRLO ${ }^{\mathrm{TM}}$ after 20 days at $360^{\circ} \mathrm{C}$, in simulated primary water.

\begin{tabular}{|l|l|l|l|l|}
\hline & $\sigma_{\mathrm{m}}(\mathbf{M P a})$ & $\boldsymbol{\sigma}_{\mathrm{t}}(\mathrm{MPa})$ & $\mathbf{f}_{\text {tet }}$ & $\boldsymbol{\sigma}_{\text {avg }}(\mathrm{MPa})$ \\
\hline Sample1 & $-1200 \pm 57$ & $-3085 \pm 163$ & 0.110 & $-1407 \pm 69$ \\
Sample2 & $-1161 \pm 45$ & $-3687 \pm 473$ & 0.120 & $-1465 \pm 96$ \\
Sample3 & $-1133 \pm 48$ & $-3264 \pm 419$ & 0.123 & $-1396 \pm 94$ \\
Sample4 & $-1357 \pm 38$ & $-3267 \pm 336$ & 0.110 & $-1568 \pm 71$ \\
Sample5 & $-1267 \pm 60$ & $-3020 \pm 292$ & 0.099 & $-1441 \pm 83$ \\
\hline
\end{tabular}

Table 3 Weibull parameters and average fracture strain and strength after removal of the residual strain

\begin{tabular}{|c|c|c|c|c|c|c|c|}
\hline \multicolumn{3}{|c|}{} & \multicolumn{2}{c|}{ 2-Parameter } & \multicolumn{3}{c|}{ 3-Parameter } \\
\hline & $\varepsilon_{\text {avg11 }}$ & $\begin{array}{c}\sigma_{11 \mathrm{~min}} \\
(\mathrm{GPa})\end{array}$ & $\sigma_{0}(\mathrm{GPa})$ & $\mathrm{m}$ & Set 1-m & $\begin{array}{c}\text { Set 2 - } \sigma_{0} \\
(\mathrm{GPa})\end{array}$ & Set 2 - m \\
Pickled & 0.0061 & 0.41 & 1.12 & 2.9 & 2.1 & 1.12 & 2.1 \\
Polished & 0.0095 & 1.05 & 1.57 & 6.4 & 2.6 & 1.56 & 2.6 \\
\hline
\end{tabular}




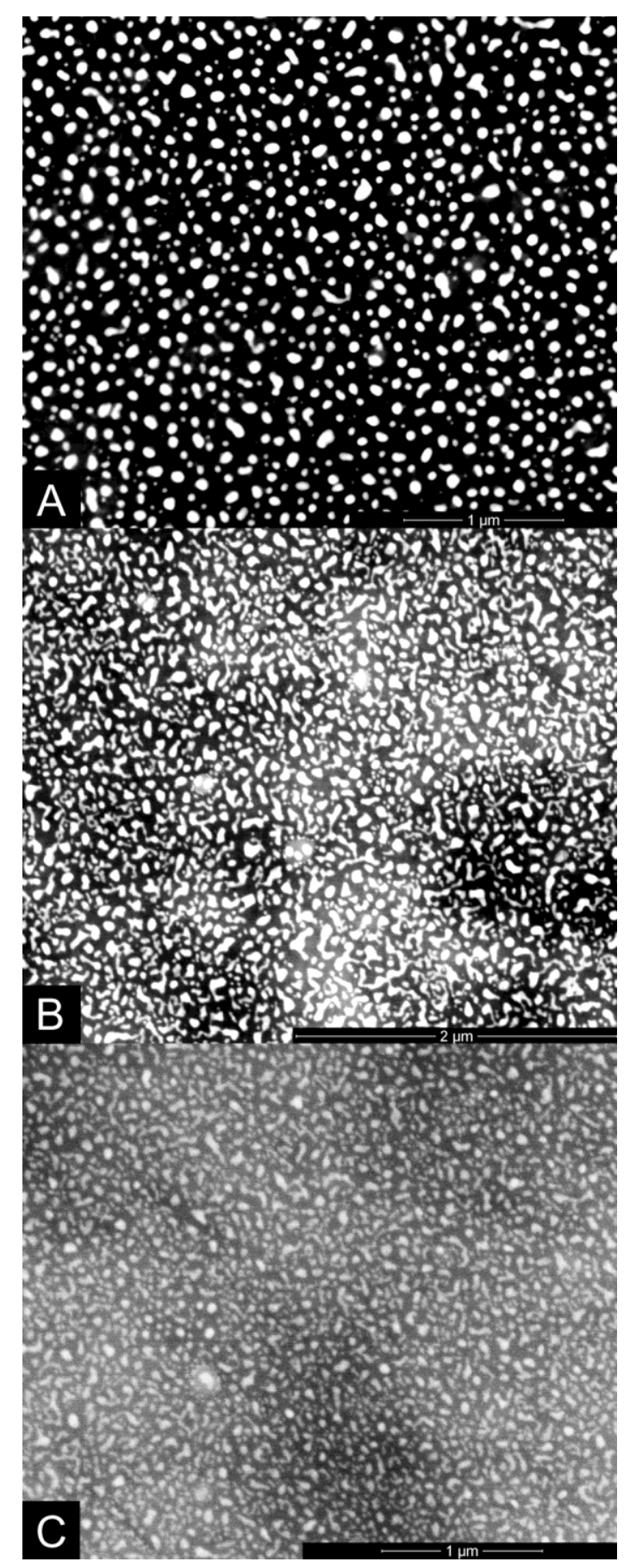

Figure 1 Backscattered Electron image of a gold remodelled pattern formed on an oxide grown on a ZIRLO $^{\text {TM }}$ substrate; A - polished (WD $6.8 \mathrm{~mm}$ ), B - pickled (WD $6.7 \mathrm{~mm}$ ), C - pickled (working distance 20.1 $\mathrm{mm}$ ) 


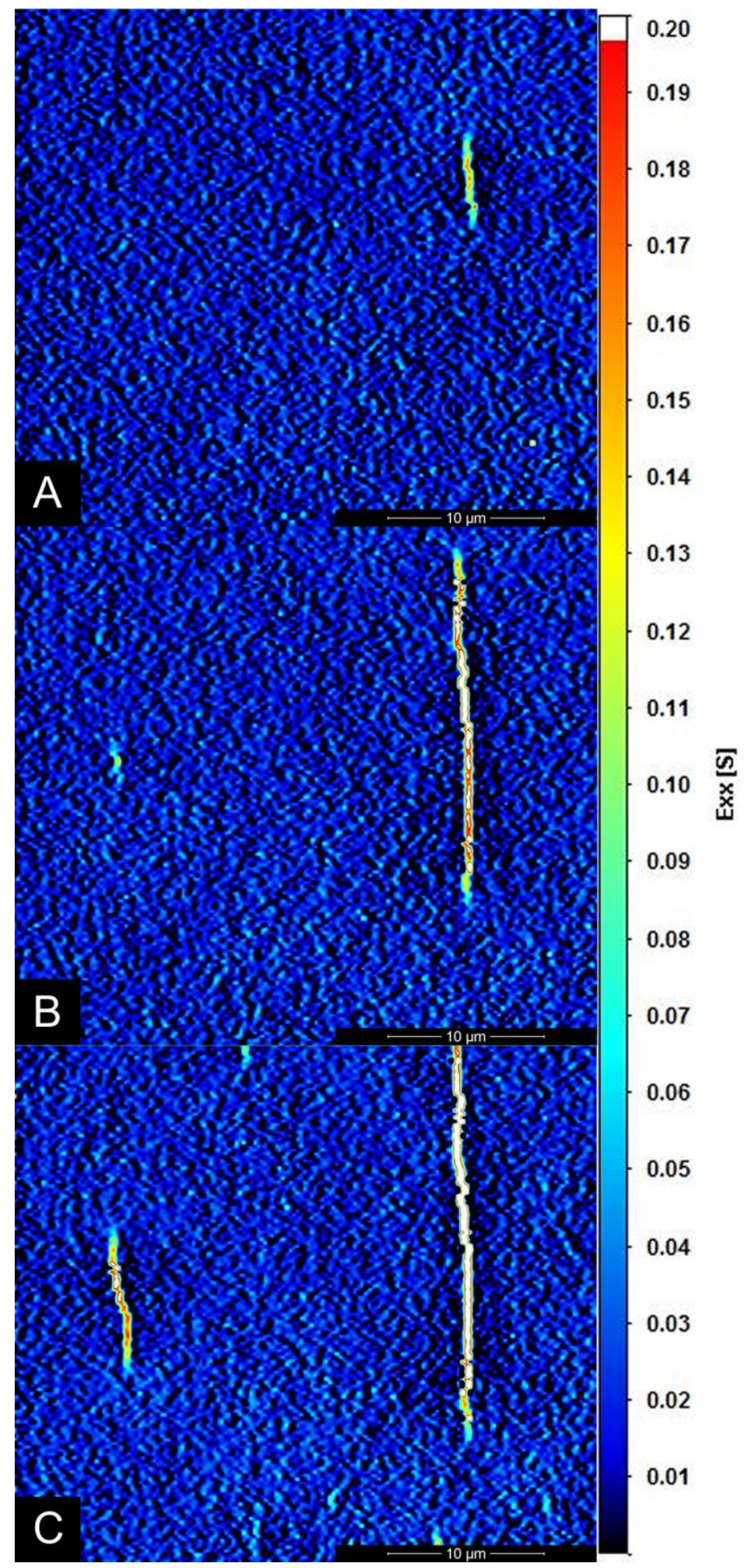

Figure 2: Shows DIC $\varepsilon_{x x}$ strain maps for a region of the oxide surface under strains of $1.3 \%$ (A), $1.4 \%$ (B), and $1.58 \%(C)$. The loading direction is perpendicular to the direction of the cracks. 


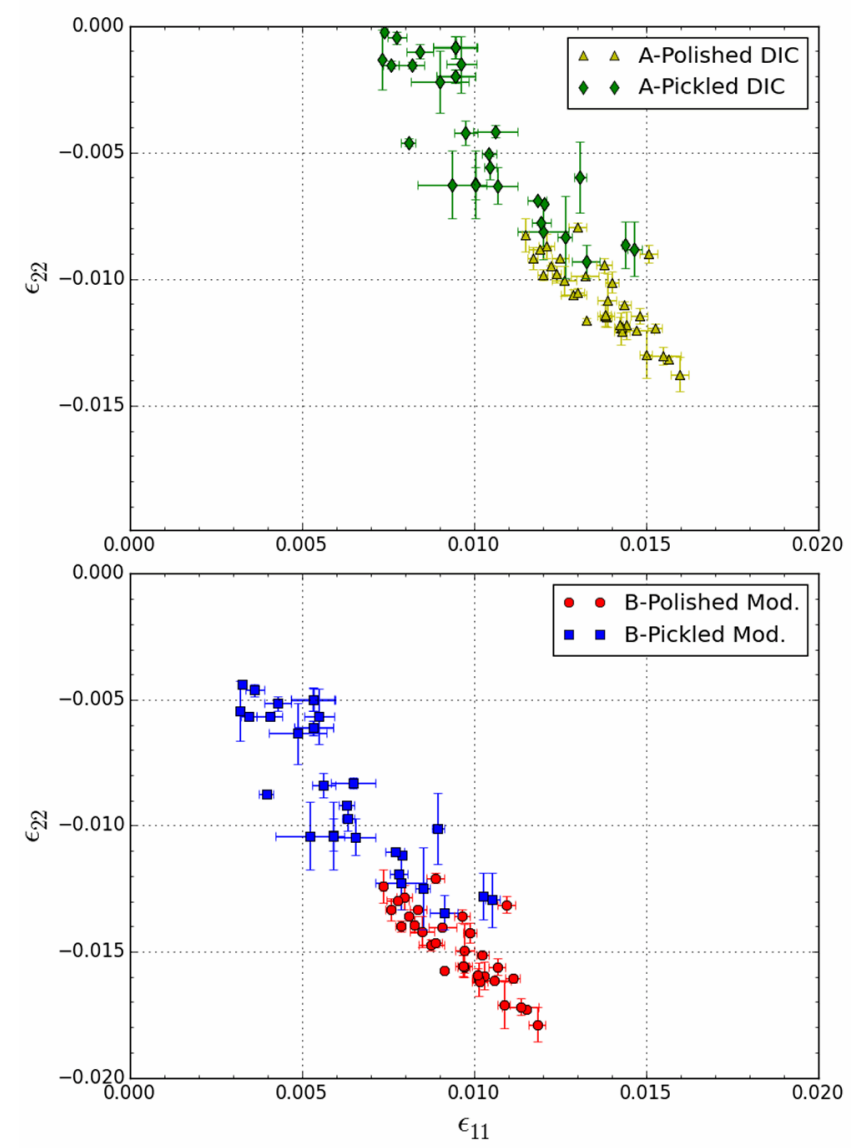

Figure 3: Shows the $\varepsilon_{11}$ and $\varepsilon_{22}$ strains at fracture recorded for oxides formed on pickled and polished surface, before (DIC) and after (Mod.) corrected for the residual strain.

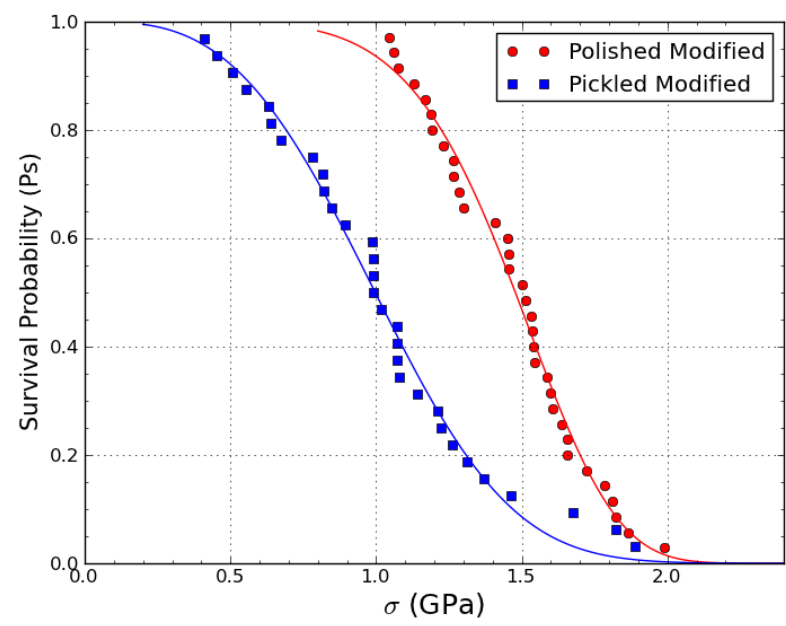

Figure 4: Fracture stresses recorded for oxides formed on pickled and polished surface, plotted against the failure probability, corrected for the residual stress. 


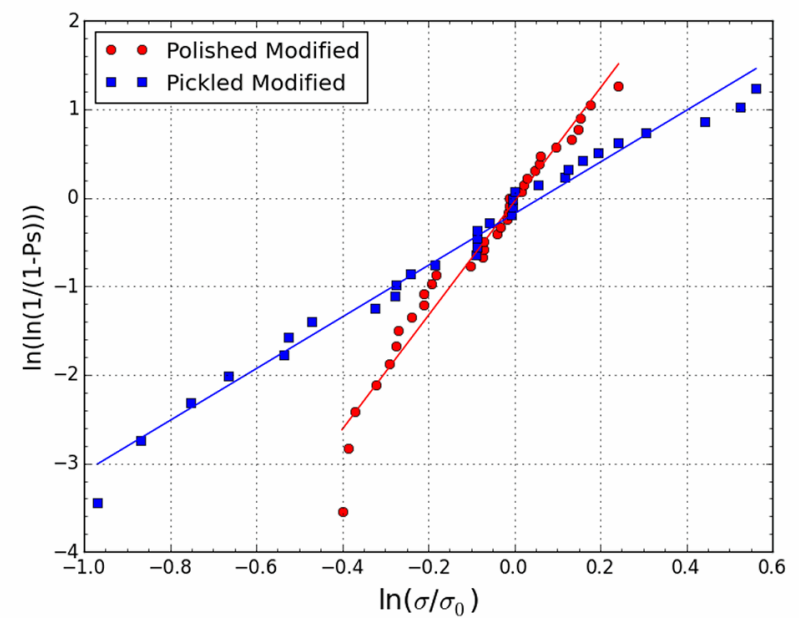

Figure 5: Shows the graphical method used to determine the constant $\mathrm{m}$ from the gradients.

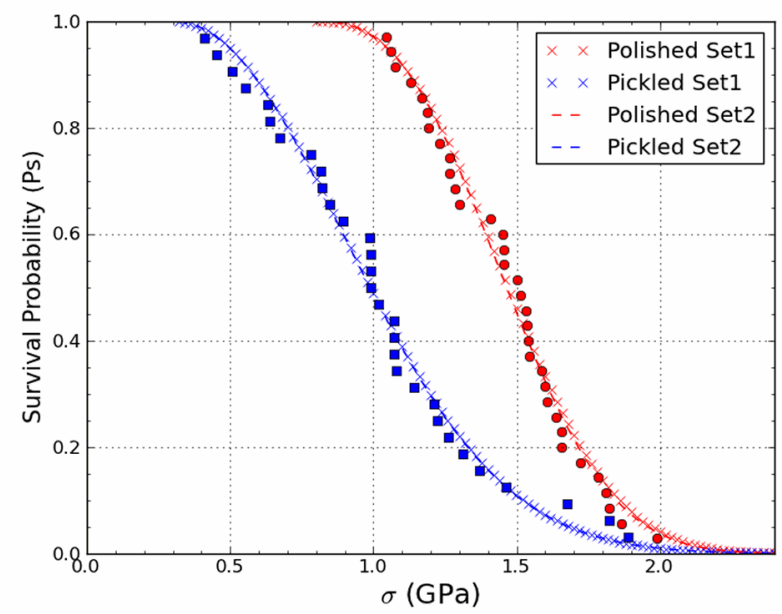

Figure 6: Results of the 3-Parameter Weibull non-linear least squares regression. $\sigma_{\min }$ is set to $0.3 \& 0.8$ GPa for Pickled and Polished Samples. In Set $1 \sigma_{0}$ is set at 1.12 \&1.57 GPa for Pickled and Polished Samples. In Set 2 both $\sigma_{0} \& \mathrm{~m}$ are allowed to vary. 


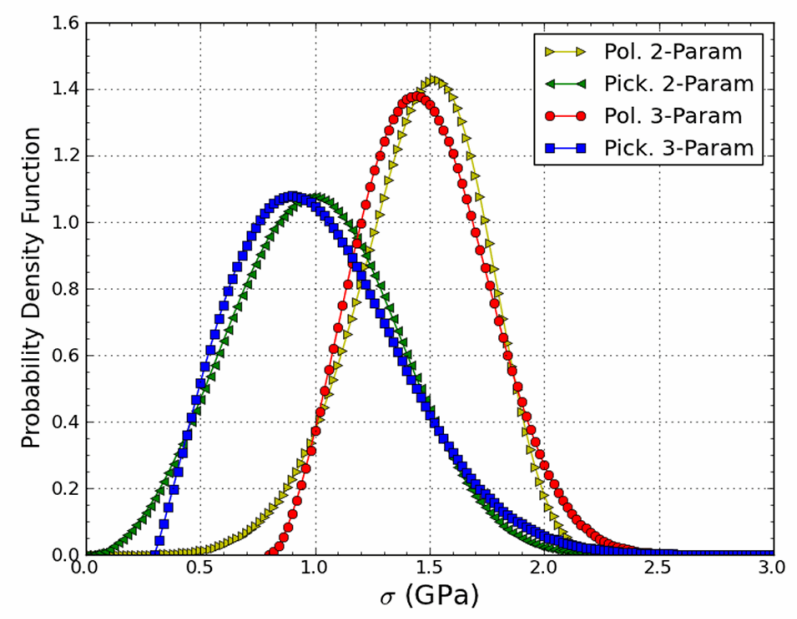

Figure 7: Probability density functions using $2 \& 3$ parameter models for samples of ZIRLOTM that have been pickled and polished prior to oxidation. 


\section{References}

[1] B.F. Kammenzind, D.G. Franklin, H.R. Peters, W.J. Duffin, in:, Zircon. Nucl. Ind. Elev. Int. Symp., n.d., pp. 338-370.

[2] P. Bossis, B. Verhaeghe, S. Doriot, Zircon. Nucl. Ind. 15th Int. Symp. ASTM STP 15056 (2007).

[3] P. Platt, E. Polatidis, P. Frankel, M. Klaus, M. Gass, R. Howells, M. Preuss, J. Nucl. Mater. 456 (2015) 415.

[4] P. Barberis, V. Rebeyrolle, J. Vermoyal, in:, Zircon. Nucl. Ind. 15th Int. Symp. ASTM STP 1505, 2007, pp. 612-631.

[5] M. Steinbrück, Oxid. Met. 70 (2008) 317.

[6] M. Preuss, P. Frankel, S. Lozano-Perez, D. Hudson, E. Polatidis, N. Ni, J. Wei, C. English, S. Storer, K.B. Chong, M. Fitzpatrick, P. Wang, J. Smith, C. Grovenor, G. Smith, J. Sykes, B. Cottis, S. Lyon, L. Hallstadius, R.J. Comstock, A. Ambard, M. Blat-Yrieix, in:, Zircon. Nucl. Ind. 16th Int. Symp. ASTM STP 1529, 2011, pp. 649-681.

[7] P. Platt, P. Frankel, M. Gass, M. Preuss, J. Nucl. Mater. 464 (2015) 313.

[8] J. Wei, P. Frankel, M. Blat, A. Ambard, R.J. Comstock, L. Hallstadius, S. Lyon, R.A. Cottis, M. Preuss, Corros. Eng. Sci. Technol. 47 (2012) 516.

[9] B. Wadman, Mechanisms of Uniform Corrosion of Zirconium Alloys in Water and Steam, Chalmers University of Technology, 1993.

[10] P. Bouvier, J. Nucl. Mater. 300 (2002) 118.

[11] A. Yilmazbayhan, A. Motta, R.J. Comstock, G.P. Sabol, B. Lai, Z. Cai, J. Nucl. Mater. 324 (2004) 6.

[12] A. Yilmazbayhan, E. Breval, A. Motta, R. Comstock, J. Nucl. Mater. 349 (2006) 265.

[13] J. Park, S. Yoo, B. Choi, Y. Jeong, J. Alloys Compd. 437 (2007) 274.

[14] H.X. Zhang, D. Fruchart, E.K. Hill, L. Ortega, Z.K. Li, J.J. Zhang, J. Sun, L. Zhou, J. Nucl. Mater. 396 (2010) 65.

[15] P. Bossis, G. Lelievre, in:, Zircon. Nucl. Ind. 12th Int. Symp. ASTM STP 1354, Astm Intl, 2000, pp. 918-945.

[16] P. Platt, S. Wedge, P. Frankel, M. Gass, R. Howells, M. Preuss, J. Nucl. Mater. 459 (2015) 166.

[17] P. Bossis, F. Lefebvre, P. Barbéris, A. Galerie, Mater. Sci. Forum 369-372 (2001) 255.

[18] N. Ni, S. Lozano-Perez, J.M. Sykes, G.D.W. Smith, C.R.M. Grovenor, Corros. Sci. 53 (2011) 4073.

[19] P. Tejland, H.-O. Andrén, J. Nucl. Mater. 430 (2012) 64.

[20] P. Platt, P. Frankel, M. Gass, R. Howells, M. Preuss, J. Nucl. Mater. 454 (2014) 290. 
[21] C. Duriez, T. Dupont, B. Schmet, F. Enoch, J. Nucl. Mater. 380 (2008) 30.

[22] H.H. Kim, J.H. Kim, J.Y. Moon, H.S. Lee, J.J. Kim, Y.S. Chai, J. Mater. Sci. Technol. 26 (2010) 827.

[23] M. Lasserre, V. Peres, M. Pijolat, O. Coindreau, C. Duriez, J.-P. Mardon, Mater. Corros. (2013) n/a.

[24] V. Parry, M.T. Tran, Y. Wouters, Oxid. Met. 79 (2013) 279.

[25] A.H. Omar, P. Véronique, S. Eric, G. François, K. Jean, R. François, C. Michel, J. Nucl. Mater. 461 (2015) 365.

[26] H. Jin, W.-Y. Lu, S. Haldar, H. a. Bruck, J. Mater. Sci. 46 (2011) 6596.

[27] F. Di Gioacchino, J. Quinta da Fonseca, Exp. Mech. 53 (2013) 743.

[28] M. Mostafavi, T.J. Marrow, Fatigue Fract. Eng. Mater. Struct. 35 (2012) 695.

[29] J. Wei, P. Frankel, E. Polatidis, M. Blat, A. Ambard, R.J. Comstock, L. Hallstadius, D. Hudson, G.D.W. Smith, C.R.M. Grovenor, M. Klaus, R.A. Cottis, S. Lyon, M. Preuss, Acta Mater. 61 (2013) 4200 .

[30] E. Polatidis, P. Frankel, J. Wei, M. Klaus, R.J. Comstock, A. Ambard, S. Lyon, R.A. Cottis, M. Preuss, J. Nucl. Mater. 432 (2013) 102.

[31] C. Genzel, I.A. Denks, J. Gibmeier, M. Klaus, G. Wagener, Nucl. Instruments Methods Phys. Res. Sect. A Accel. Spectrometers, Detect. Assoc. Equip. 578 (2007) 23.

[32] R. Garvie, P. Nicholson, J. Am. Ceram. Soc. (1972) 303.

[33] A.G. Evans, G.B. Crumley, R.E. Demaray, Oxid. Met. 20 (1983) 193.

[34] LaVision, (2015).

[35] L. Afferrante, M. Ciavarella, E. Valenza, Int. J. Solids Struct. 43 (2006) 5147.

[36] M.R. Wenman, Eng. Fract. Mech. 98 (2013) 350.

[37] X.. Zhang, J.. Knott, Acta Mater. 48 (2000) 2135.

[38] J. Eichler, J. Rödel, U. Eisele, M. Hoffman, J. Am. Ceram. Soc. 90 (2007) 2830.

[39] K. Noguchi, M. Fujita, J. Am. Ceram. Soc. (1989) 1305.

[40] J. Eichler, U. Eisele, J. Rödel, J. Am. Ceram. Soc. 87 (2004) 1401.

[41] A. Garner, A. Gholinia, P. Frankel, M. Gass, I. MacLaren, M. Preuss, Acta Mater. 80 (2014) 159.

[42] N. Ni, D. Hudson, J. Wei, P. Wang, S. Lozano-Perez, G.D.W. Smith, J.M. Sykes, S.S. Yardley, K.L. Moore, S. Lyon, R. Cottis, M. Preuss, C.R.M. Grovenor, Acta Mater. 60 (2012) 7132.

[43] N. Ni, S. Lozano-Perez, M.L. Jenkins, C. English, G.D.W. Smith, J.M. Sykes, C.R.M. Grovenor, Scr. Mater. 62 (2010) 564. 
[44] P. Platt, V. Allen, M. Fenwick, M. Gass, M. Preuss, Corros. Sci. 98 (2015) 1.

[45] M. Parise, O. Sicardy, G. Cailletaud, J. Nucl. Mater. 256 (1998) 35.

[46] J. Chevalier, L. Gremillard, A. V. Virkar, D.R. Clarke, J. Am. Ceram. Soc. 92 (2009) 1901. 